\title{
Ionic Liquids:- As Energy Efficient Solvent For The Extractive Desulfurization of Liquid Fuels
}

\author{
Swapnil A. Dharaskar ${ }^{*}$, Samir K. Deshmukh ${ }^{1}$, Kiran D. Bhuyar ${ }^{1}$, Kailas L. Wasewar ${ }^{2}$
}

\begin{abstract}
A new class of energy efficient solvent, known as ionic liquids, has recently been the subject of demanding research on the extractive desulfurization of liquid fuels. The aim of this study is to investigate the possible application of ionic liquids as green energy efficient solvent because of their unique physical and chemical properties. In this work, Imidazolium based 1-butyl-3methyllimidazolium hexfluorophosphate [BMIM] $\mathrm{PF}_{6}$ and 1-butyl-3methyllimidazolium tetrafluoroborate $[\mathrm{BMIM}] \mathrm{BF}_{4}$ were synthesized and employed as extractive agent for the removal of sulfur compounds. The effects of reaction time, reaction temperature, sulfur compounds, and recycling of ionic liquids without regeneration on dibenzothiphene removal of liquid fuel were presented. Also, the desulfurization of real fuels was investigated. The data and results of presented work might be provide significant insights of imidazoled ILs as green solvent for extractive desulfurization of liquid fuels as it can be reused to four cycle without regeneration with considerable extraction efficiency.
\end{abstract}

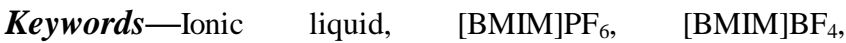
Desulfurization, Liquid Fuel, Extraction

\section{INTRODUCTION}

$\mathrm{S}$ ULFUR containing compounds in transportation fuels are converted to $\mathrm{SO}_{\mathrm{x}}$ by combustion, which is a major source of acid rain and air pollution [1]. For environmental protection purpose [2], many countries have mandated reduction of S-level in fuels down to $10 \mathrm{ppm}$ by 2012 [3], and with more stringent regulatory constraint, it is a trend to achieve little to no sulfur fuels in the next several years [4]. In India, the present norms were decided by Central Pollution Control Board, the current value of total sulfur in liquid fuels is limited to $350 \mathrm{ppm}$ which has to be lower down into possible extent. At present, the removal of S-containing compounds is carried out by a catalytic hydrodesulfurization (HDS) [5]. It requires severe conditions of high temperature and high hydrogen pressure to produce low sulfur light fuel [6]. The efficiency of HDS is limited to treat DBT and its derivatives, owing to their stereo hindrance on the $\mathrm{S}$-atom [7].

Several technologies such as extractive desulfurization, elective adsorption, catalytic oxidation, and biodesulfurization were applied. In petroleum and hydrocarbon industries, various solvents such as ethers, amines, alcohols and other

Dr. Swapnil Dharaskar, ${ }^{1}$ Assistant Professor, Department of Chemical Engineering, Priyadarshini Institute of Engineering \& Technology, Nagpur (M.S) India-440019

Dr. Kailas Wasewar ${ }^{2}$, Associate Professor \& Head, Department of Chemical Engineering, Visvesvaraya National Institute of Engineering \& Technology, Nagpur (M.S) India-440010( volatile organic compounds have been used for the options like extraction, absorption, azeotropic distillation etc [8]. Conventional solvents have their own limitations in terms of environmental issue, recycle ability, etc. which can be overcome by the use of ILs as green solvent [9]. Few processes are highly energy intensive and consume large amount of hydrogen, so it is difficult to generalize. Among these, deep extractive desulfurization (EDS) is an attractive technology, as it can be carried out at ambient temperature, pressure, and without hydrogen as a catalyst. A good extractant must have good extractive ability for S-compounds, free of contamination to the fuels, non-toxicity, environmental benignity, and stability for repetitive use. ILs have been studied for many possible applications for green chemical processes [10], such as an ion conductive matrix [11] as well as reaction solvent $[12,13]$ due to their unique physical properties, a wide liquid range, high ionic conductivity, a wide voltage windows and non-volatility [14].

ILs is usually composed of heterocyclic organic cations and various anions. ILs can be liquid at low of temperatures of $96^{\circ} \mathrm{C}$ and some are at over $400^{\circ} \mathrm{C}[15,16]$. ILs can be easily synthesized for any specific application either by careful selection of cation or anion or both, or by attaching new functional groups, such as amide, nitrile, amine, sulfonic acid, ether, alcohol, carboxylic, and thiols, to the structure to impart the desired properties [17, 18].

In present work, imidazolium based 1-butyl-3methyllimidazolium hexfluorophosphate $\left[\mathrm{BMIM} \mathrm{PF}_{6}\right.$ and 1butyl-3-methyllimidazolium tetrafluoroborate $[\mathrm{BMIM}] \mathrm{BF}_{4}$ were synthesized and employed as extractive agent for the removal of S-compounds. Synthesized IL has been used as energy efficient solvent for the possible application in desulfurization of liquid fuel.

\section{II.EXPERIMENTAL}

\subsection{Chemical and Materials}

IL used in the experiment was synthesized using analytical grade chemicals. The details of the chemical used are as follows: 1-methylimidazole (Acros, 99\%), 1-bromobutatne (Acros, min 99\%), $\mathrm{NaBF}_{4}$ (Sigma Aldrich, 98\%), $\mathrm{KPF}_{6}$ (Sigma Aldrich, 98\%), Acetone (SDFCL, 99.5\%), Ethyl Acetate (SDFCL, 99.5\%), dibenzothiophene (DBT) (Acros, 98\%), n-Ocatne (Acros, 99\%), Benzothiophene (BT) (Sigma Aldrich, 99\%), Thiophene (T) (Sigma Aldrich, 99\%), 3methylthiophene (3-MT) (Sigma Aldrich, 98\%). All chemicals were used without any further purification. Real fuels were purchased from Local Petroleum Pump House, Nagpur, Maharashtra (India). 


\subsection{Preparation of Imidazoilum ILs.}

\subsubsection{Synthesis of [BMIM]BF 4}

$6.57 \mathrm{~g}(0.03 \mathrm{~mol})$ [BMIM]Br and $3.29 \mathrm{~g}(0.03 \mathrm{~mol}) \mathrm{NaBF}_{4}$ added to the single mouth flask with definite amount of acetone as solvent, for $10 \mathrm{~h}$ at $40^{\circ} \mathrm{C}$ under vigorous stirring. The reaction mixture was filtered, and vacuum distilled. Dichloromethane added to the resulting mixture of [BMIM] Br and $\mathrm{NaBF}_{4}$, and white solids precipitated were obtained. Then, the solids precipitate was separated by filtration. Finally, the product was vacuum dried oven at $80^{\circ} \mathrm{C}$ for $2 \mathrm{~h}$ to remove the traces of dichloromethane [19].

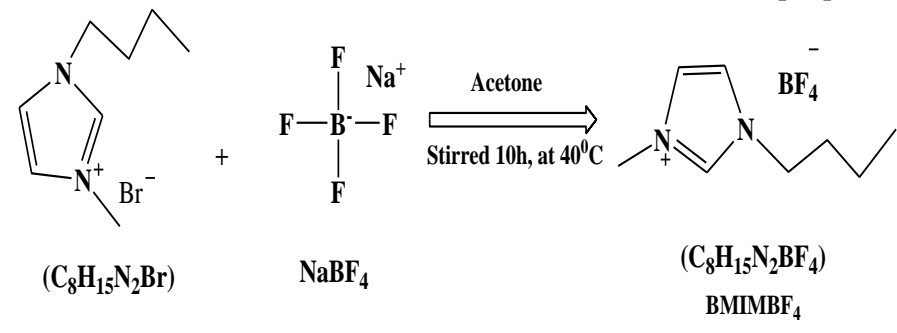

Scheme 1. Synthesis route of $[\mathrm{BMIM}] \mathrm{BF}_{4}$.

\subsubsection{Synthesis of [BMIM]PF 6}

$5.52 \mathrm{~g}(0.03 \mathrm{~mol}) \mathrm{KPF}_{6}$ dissolved in appropriate amount of distilled water in a single neck flask, and then added $0.03 \mathrm{~mol}$ of [BMIM] Br stirred for $5 \mathrm{~h}$ at $40^{\circ} \mathrm{C}$. An oil phase appeared at the bottom of the flask. Got the oil phase by dumping out the water phase, and washed repeatedly the oil phase. Finally, place the synthesized IL in a vacuum drying oven, drying at $80^{\circ} \mathrm{C}$ until weight keep [19].

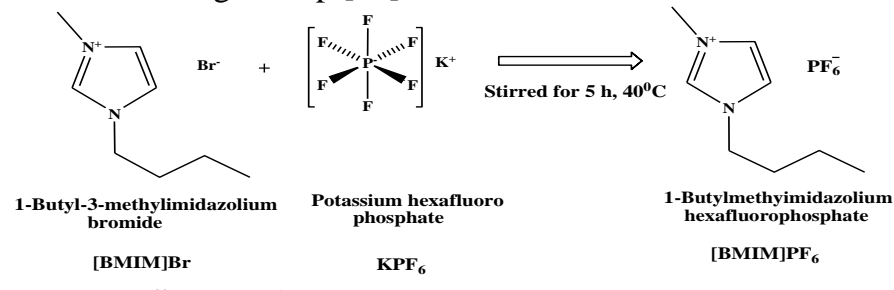

Scheme 2. Synthesis route of [BMIM] $\mathrm{PF}_{6}$.

\subsection{Model Liquid Fuel Preparation}

A model liquid fuel with 500 ppmw sulfur (DBT as sulfur source) was prepared in n-Octane. Similarly, the model liquid fuels were prepared by dissolving $\mathrm{BT}, \mathrm{T}$, and 3-MT individually in n-Octane respectively. Actual diesel and gasoline with total sulfur content of 385.13 and 180.79 ppmw respectively were used.

\subsection{Extractive Deep-Desulfurization}

$100 \mathrm{ml}$ two necked flask were used for the extractive desulfurization experiments where $10 \mathrm{ml}$ model liquid fuel and define amount of IL with mass ratio (model fuel to IL as 5:1) were mixed by vigorous stirring for time range between 5-30 min at $30^{\circ} \mathrm{C}$ in a water bath. The upper phase (model liquid fuel) was separated after completion of the reaction and settling of the reaction mixture. The upper phase (fuel phase) was analyzed for the S-content. The extraction efficiency is presented in terms of the S-removal based on the initial and final S-content in the fuel.

\subsection{Instrumentation}

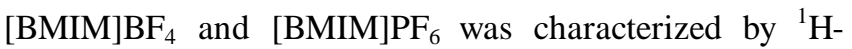
NMR and ${ }^{13} \mathrm{C}$-NMR using $\mathrm{CDCl}_{3}$ as solvent on a (Varian, USA Mercury plus $300 \mathrm{MHz}$ for ${ }^{1} \mathrm{H}-\mathrm{NMR}$ and $76 \mathrm{MHz}$ for

${ }^{13} \mathrm{C}$-NMR spectrometer) for determination of molecular

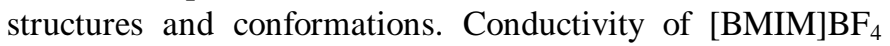
and $[\mathrm{BMIM}] \mathrm{PF}_{6}$ was measured by $\mathrm{PICO}^{+}$(Lab India)

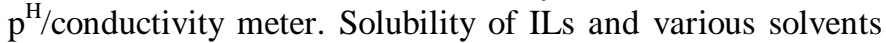
are placed into a $50 \mathrm{ml}$ round bottom flask, magnetically stirred and allowed to settle. After phase equilibrium and splitting, the top layer was analyzed by high performance liquid chromatography (HPLC). The S-content in model liquid fuel and real fuels before and after extraction was analyzed by X-Ray Fluorescence Spectrometer (XRF), Model PW 2404, Phillips (now, PANAlytical, The Spectris Technology, Netherlands), Centre of Sophisticated Analytical Instrumental Facility, Indian Institute of Technology (IIT), Mumbai (M.S.) India. The contact time of 30 min between the model fuel and IL phase is more than enough to achieve the equilibrium. So the optimum time required for the desulfurization of model fuel was $30 \mathrm{~min}$. However, $[\mathrm{BMIM}] \mathrm{BF}_{4}$ and $[\mathrm{BMIM}] \mathrm{PF}_{6}$ was best suitable to remove DBT reflected at $35^{\circ} \mathrm{C}$ which was taken as the optimal reaction temperature.

\section{Result AND DisCUSSION}

\subsection{Characterization of IL}

${ }^{1} \mathrm{H}-\mathrm{NMR}$, and ${ }^{13} \mathrm{C}-\mathrm{NMR}$ analysis were carried out for characterization of $\mathrm{IL}$. The production of pure IL is very important since impurities have a strong influence on their physical properties and stability.

\subsection{1. ${ }^{1} \mathrm{H}$-NMR and ${ }^{13} \mathrm{C}$-NMR Analysis}

For all NMR analysis, approximately $30 \mathrm{mg}$ of the IL was added into a $5 \mathrm{~mm}$ NMR tube. A stem coaxial capillary tube loaded with $0.5 \mathrm{~mL}$ of solute was inserted into the $5 \mathrm{~mm}$ NMR tube. ${ }^{1} \mathrm{H}-\mathrm{NMR}$ data in $\mathrm{ppm}(\delta)$ from the internal standard (TMS, $0.0 \mathrm{ppm}$ ), chemical shift (multiplicity, integration), and the ${ }^{13} \mathrm{C}-\mathrm{NMR}$ data in ppm $(\delta)$ were reported. The results of ${ }^{1} \mathrm{H}-\mathrm{NMR}$ and ${ }^{13} \mathrm{C}-\mathrm{NMR}$ analysis of [BMIM] $\mathrm{BF}_{4}$ and $[\mathrm{BMIM}] \mathrm{PF}_{6}$ are given as follows:-

[BMIM]BF ${ }_{4}$ :- ${ }^{1} \mathbf{H N M R}\left(300 \mathrm{MHz}, \mathrm{CDCl}_{3}\right):$ of $(\mathrm{ppm})=$ $7.916(2,1 \mathrm{H}, \mathrm{t}), 4.191(4,2 \mathrm{H}, \mathrm{t}), 1.864(5,2 \mathrm{H}, \mathrm{tt}), 1.333(6$, $2 \mathrm{H}, \mathrm{tq}), 0.873(7,3 \mathrm{H}, \mathrm{t}), 7.371$ (8, 1H, dd), $7.172(9,1 \mathrm{H}, \mathrm{dd}$,), $3.962(10,3 \mathrm{H})$.

${ }^{13}$ CNMR (76 MHz, $\left.\mathrm{CDCl}_{3}\right)$ : d (ppm) 135.99, 123.80, 126.5, 49.57, 31.86, 19.25, 13.27, 36.04.

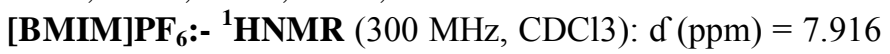
$(2,1 \mathrm{H}, \mathrm{t}), 4.089(4,2 \mathrm{H}, \mathrm{t}), 1.787(5,2 \mathrm{H}, \mathrm{tt}), 1.265(6,2 \mathrm{H}, \mathrm{tq})$, $0.852(7,3 \mathrm{H}, \mathrm{t}), 7.311(8,1 \mathrm{H}, \mathrm{dd}), 7.224(9,1 \mathrm{H}, \mathrm{dd}), 3.833$ $(10,3 \mathrm{H})$. 
${ }^{13}$ CNMR (76 MHz, CDCl3): d (ppm) 135.64, 123.61, $122.35,49.63,31.65,19.17,13.14,35.91$.

\subsubsection{Conductivity Analysis}

IL conductivity mainly depends on mobility of its cation because the diffusion coefficients of ILs cations are higher than anions. ILs based on imidazolium cations has the highest ionic conductivity. ILs showing the highest conductivities, e.g. 1-ethyl-3-methylimidazolium thiocyanate and dicyanamide exhibit the lowest electrochemical stabilities. When conductivity and thermal stability are both required in a separation or extraction process, imidazolium based ILs with stable anions e.g., tetrafluoroborate or hexafluorophosphate are applied [20]. [BMIM] $\mathrm{BF}_{4}$ and [BMIM] $\mathrm{PF}_{6}$ shows conductivity value of 1180 and 860 $\left(\mu \mathrm{s} \cdot \mathrm{cm}^{-1}\right)$ respectively which is comparatively small. After exchanging of anion, the conductivity of IL could be increases. So, IL has great advantages as compared to conventional organic solvents [21].

\subsubsection{Solubility Analysis}

The solubility of imidazolium IL with six conventional solvents was studied. ILs may be dissolved in some conventional organic solvents such as methanol, acetonitrile, ethanol, acetone and water, but not all the organic solvents (e.g. IL not dissolved in ethyl acetate). The ILs solubility might be changed by changing the anions. Novel two-phase system can be created and used for various applications such as synthesis and extraction [22]. For the application of IL extractant the solubility mechanism of IL is needed. Imidazolium ILs solubility in liquid fuel may give rise to extractant loss and liquid fuel contamination. This results suggest that the solubility of imidazolium based IL in liquid fuel has to be optimized for future applications.

\subsection{Effect of Reaction Time on S-removal}

The extractions of model fuel (DBT in n-Octane) with

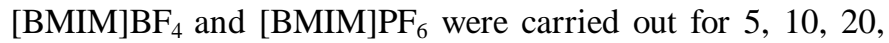
and $30 \mathrm{~min}$ at $30^{\circ} \mathrm{C}$ with mass ratio of $5: 1$, (Mass ratio of model liquid fuel to IL) as shown in Table 1. The desulfurization process went quiet quickly and Sconcentration in model fuel decreased with increased in extraction time and was reduced from 500 to $184.55 \mathrm{ppmw}$ (S-removal 63\%) in [BMIM]BF 4 and $194 \mathrm{ppmw}$ (S-removal $61.2 \%$ ) $\left[\mathrm{BMIM} \mathrm{PF}_{6}\right.$ with mass ratio of 5:1 respectively in 20 min. Consequently, S-concentration decreased continuously with increased in extraction time and reduced from 500 to $170 \mathrm{ppmw}$ (S-removal 66\%) in [BMIM] $\mathrm{BF}_{4}$ and $181.5 \mathrm{ppmw}$ (S-removal $63.5 \%$ ) in [BMIM] $\mathrm{PF}_{6}$ with mass ratio of 5:1 respectively in $30 \mathrm{~min}$. At the initial stage of the reaction, Scontent in the model fuel was very high hence the extraction rate becomes high with high S-removal rate. As the reaction proceeds extraction rate becomes low with S-removal rate no longer distinctly increases. The results, in Table 1 , show that contact time of $30 \mathrm{~min}$ between the model liquid fuel and IL phase is more than enough to achieve the equilibrium. So the optimum time required for the desulfurization of model fuel was $30 \mathrm{~min}$. The imidazolium ILs are more capable of efficiently extracting DBT than other S-containing compounds [23]. This observation was also reported in other ILs extraction process for imidazolium ILs was attributed for higher polarisable $\pi$-electron density of DBT which tends to insert the molecular structure of ILs [24]. DBT extraction

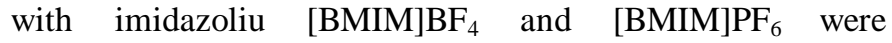
recognized to the $\pi-\pi$ interaction between the aromatic ring of imidazolium and the thiophenic ring of DBT. The better DBT removal ability of $[\mathrm{BMIM}] \mathrm{BF}_{4}$ and $[\mathrm{BMIM}] \mathrm{PF}_{6}$ likely to enhanced $\pi-\pi$ interactions, since, the cations $(-\mathrm{C} \equiv \mathrm{N})$ group

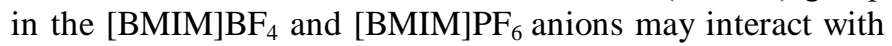
the thiophenic ring of DBT [25].

This experiment clearly demonstrates that the extraction ability of imidazolium ILs was satisfactory in comparison with other ILs and has the highest partition coefficient $\left(\mathrm{K}_{\mathrm{N}}\right)$ of DBT. In Table 1, Nernst partition coefficient $\left(\mathrm{K}_{\mathrm{N}}\right)$ is given to specify the extractive ability of imidazolium ILs for DBT with mass ratios of $5: 1 . \mathrm{K}_{\mathrm{N}}$ was calculated by the ratio of $\mathrm{S}$ concentration in IL to S-concentration in model fuel. $\mathrm{K}_{\mathrm{N}}$ is a key parameter to determine the extractive ability of one extractant in an industrial extraction process. Higher the partition coefficient is, the better the desulfurization performance of an ILs [26].The structures and sizes of both the cations and anions in ILs have a strong impact on their extractive performance.

\begin{tabular}{|c|c|c|c|c|}
\hline \multicolumn{1}{c|}{ IL } & $\begin{array}{c}\text { Time } \\
(\mathbf{m i n})\end{array}$ & $\begin{array}{c}\text { S-content } \\
(\mathbf{p p m w})\end{array}$ & $\begin{array}{c}\text { S- } \\
\text { removal } \\
(\mathbf{\%})\end{array}$ & $\left(\mathbf{K}_{\mathbf{N}}\right)$ \\
\hline \multirow{3}{*}[\mathrm{BMIM}^{\mathbf{n}}]{$\mathrm{BF}_{4}$} & 10 & 199.05 & 60.2 & 1.51 \\
\cline { 2 - 5 } & 20 & 184.55 & 63 & 1.71 \\
\cline { 2 - 5 } & 30 & 170.05 & 66 & 1.94 \\
\hline \multirow{3}{*}[\mathrm{BMIM}]{$\mathrm{PF}_{6}$} & 5 & 223.55 & 55.3 & 1.24 \\
\cline { 2 - 5 } & 10 & 209.55 & 58 & 1.39 \\
\cline { 2 - 5 } & 20 & 194.05 & 61.2 & 1.58 \\
\cline { 2 - 5 } & 30 & 181.5 & 63.7 & 1.75 \\
\hline
\end{tabular}

Temperature $=30^{\circ} \mathrm{C}$, Mass ratio of model fuel $/ \mathrm{IL}=5: 1$, Extraction time $=30 \mathrm{~min}$. Initial sulfur concentration $=500 \mathrm{ppmw}$. EFFECT OF REACTION TIME ON S-REMOVAL

\subsection{Effect of Reaction Temperature on S-removal}

Reaction temperature play vital role in the extractive desulfurization process, Table 2 , shows the effect of the reaction temperature $\left(20^{\circ} \mathrm{C}, 25^{\circ} \mathrm{C}, 35^{\circ} \mathrm{C}, 45^{\circ} \mathrm{C}, 55^{\circ} \mathrm{C}\right)$ on the removal of sulfur. As shown in table 2, with the increasing reaction temperature from $20^{\circ} \mathrm{C}$ to $35^{\circ} \mathrm{C}$, the removal efficiency of sulfur increases initially and then decreased. This effect may be attributed that when the reaction temperature was less than $45^{\circ} \mathrm{C}$, as temperature increases the viscosity of IL reduced and then the flexibility of IL was also improved which may be form viscous flow layer. Thus, DBT removal efficiency in the model fuel by IL increased. When temperature exceeds $35^{\circ} \mathrm{C}$, the flexibility of $\mathrm{IL}$ is not noticeably improved. Moreover, S-removal rate will no longer increase and even to some extent decline [27]. 


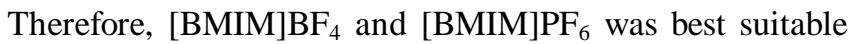
to remove DBT reflected at $35^{\circ} \mathrm{C}$ which was taken as the optimal reaction temperature. The S-content of the model fuel decreased from 500 to 165.05 ppmw (67\% S-removal) in $\left[{\mathrm{BMIM}] \mathrm{BF}_{4}}_{4}\right.$ and 171.5 ppmw $(65.7 \% \quad$ S-removal $)$ in $[\mathrm{BMIM}] \mathrm{PF}_{6}$ with mass ratio of 5:1 respectively as shown in Table 2. Significant drop in S-removal was observed when reaction temperature reached to $55^{\circ} \mathrm{C}$, and the $\mathrm{S}$-removal was

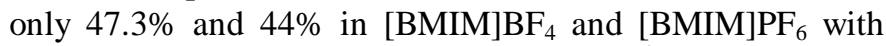
mass ratio of $5: 1$ respectively. Hence, $35^{\circ} \mathrm{C}$ is a suitable temperature in the desulfurization process. Insensitivity to temperature was also observed in other extraction systems

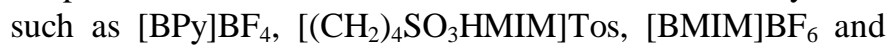
[BMIM] $\mathrm{PF}_{6}$ [25]. Subsequently, S-extraction may be performed at room temperature, which is encouraging for less energy consumption.

TABLE II

EFFECT OF REACTION TEMPERATURE ON S-REMOVAL

\begin{tabular}{|c|c|c|c|c|}
\hline IL & $\begin{array}{l}\text { Temper } \\
\text { ature } \\
\left({ }^{\mathrm{O}} \mathrm{C}\right)\end{array}$ & $\begin{array}{l}\text { S-content } \\
(\mathrm{ppmw})\end{array}$ & $\begin{array}{l}\text { S-removal } \\
(\%)\end{array}$ & $\begin{array}{l}\text { Part. Coeff. } \\
\left(K_{N}\right)\end{array}$ \\
\hline \multirow{5}{*}{$\begin{array}{c}{[\mathrm{BMIM}] \mathrm{B}} \\
\mathrm{F}_{4}\end{array}$} & 20 & 198.5 & 60.3 & 1.52 \\
\hline & 25 & 179.05 & 64.2 & 1.79 \\
\hline & 35 & 165.05 & 67 & 2.02 \\
\hline & 45 & 224.55 & 55 & 1.22 \\
\hline & 55 & 263.55 & 47.3 & 0.89 \\
\hline \multirow{5}{*}{$\begin{array}{c}{[\mathrm{BMIM}] \mathrm{P}} \\
\mathrm{F}_{6}\end{array}$} & 20 & 213.05 & 57.4 & 1.35 \\
\hline & 25 & 200.05 & 60 & 1.5 \\
\hline & 35 & 171.5 & 65.7 & 1.92 \\
\hline & 45 & 249.05 & 50.2 & 1.0 \\
\hline & 55 & 279.55 & 44 & 0.79 \\
\hline
\end{tabular}

Temperature $=30^{\circ} \mathrm{C}$, Mass ratio of model fuel/IL $=5: 1$, Extraction time $=30 \mathrm{~min}$. Initial sulfur concentration $=500 \mathrm{ppm}$.

\subsection{Effect of S-Compound on S-removal}

Table 3 represents the molecular structures and properties of S-compounds normally found in real fuels such as diesel and gasoline on extraction with pure hydrocarbons. It might be seen that results for thiols, sulfides, and related compounds are quite low. However, the results for DBT, T, BT, and 3MT are excellent. Table 3, shows that the most likely mechanism for the extraction of S-compounds with

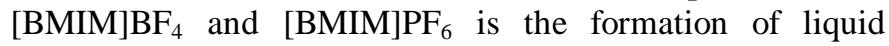
clathrates and $\pi-\pi$ interactions between aromatic structures of the extraction target and the imidazolium ring system [21]. In real fuels, many nitrogen, oxygen, and aromatic compounds have been existed, which decreased the extraction performance of the IL for S-containing compounds. In real diesel, there were different kinds of alkyl substituted DBTs are present such as BT, T, and 3-MT. The results suggested that using $[\mathrm{BMIM}] \mathrm{BF}_{4}$ and $[\mathrm{BMIM}] \mathrm{PF}_{6} \quad$ S-removal reached to $66 \%$ and $65.2 \%$ in $30 \mathrm{~min}$ at $30^{\circ} \mathrm{C}$ respectively. However, the removal of $\mathrm{BT}, \mathrm{T}$, and 3-MT were $63.9 \%, 53.8 \%$ and $47.9 \%$ in $[\mathrm{BMIM}] \mathrm{BF}_{4}$ respectively. Also, in [BMIM] $\mathrm{PF}_{6}$ it was reduced to $57.9 \%, 49.9 \%$ and $42.8 \%$ within same time respectively as shown in Table 3. compared with DBT, the electron density on the S-atom on BT, T, and 3-MT are lower, which leads to the lower reactivity of S-compounds [27]. However, the reactivity of the DBTs decreased with increasing methyl substitutes at the derivative substitute positions, the reactivity sequencing was $\mathrm{DBT}>\mathrm{BT}>\mathrm{T}>3-$ MT [28]. Table 3, it has been also observed that the removal of DBT using imidazolium ILs was much promising for Sremoval and shows the highest removal efficiency of sulfur with fixed mass ratio of model liquid fuel to ILs as 3:1 in 30 $\min$ at $30^{\circ} \mathrm{C}$.

TABLE III

EFFECT OF S-COMPOUNDS ON EXTRACTION WITH [BMIM]BF 4

\begin{tabular}{|c|c|c|c|c|}
\hline $\mathbf{L}$ & $\begin{array}{c}\text { S- } \\
\text { Compound }\end{array}$ & $\begin{array}{c}\text { S- } \\
\text { content } \\
(\text { ppmw } \\
\text { ) }\end{array}$ & $\begin{array}{l}\text { S- } \\
\text { removal } \\
(\%)\end{array}$ & $\mathbf{K}_{\mathbf{N}}$ \\
\hline \multirow[t]{4}{*}[\mathrm{BMIM}]{$\mathrm{BF}_{4}$} & DBT & 169.55 & 66 & 1.94 \\
\hline & BT & 180.49 & 63.9 & 1.77 \\
\hline & $\mathrm{T}$ & 231.09 & 53.8 & 1.16 \\
\hline & 3-MT & 260.30 & 47.9 & 0.92 \\
\hline \multirow[t]{4}{*}{${\mathrm{BMIM}] \mathrm{PF}_{6}}$} & DBT & 174.09 & 65.2 & 1.87 \\
\hline & $\mathrm{BT}$ & 210.39 & 57.9 & 1.37 \\
\hline & $\mathrm{T}$ & 250.19 & 49.9 & 0.99 \\
\hline & 3-MT & 285.79 & 42.8 & 0.75 \\
\hline \multicolumn{5}{|c|}{$\begin{array}{c}\text { Temperature }=30^{\circ} \mathrm{C}, \text { Mass ratio of model fuel } / \mathrm{IL}=3: 1, \\
\text { Extraction time }=30 \mathrm{~min} . \\
\text { Initial sulfur concentration }=500 \mathrm{ppmw} .\end{array}$} \\
\hline
\end{tabular}

\subsection{Recycling of spent ILs without Regeneration}

In practical processes, considering the high cost of ILs regeneration of ILs is needed. The S-extraction performance of the $[\mathrm{BMIM}] \mathrm{BF}_{4}$ and $[\mathrm{BMIM}] \mathrm{PF}_{6}$ without regeneration was investigated and the results are shown in Table 4, which shows the desulfurization efficiency of spent ILs without regeneration was reused upto four cycles. It was seen that the spent IL was able to remove DBT from liquid fuel even without regeneration, nevertheless, at a lower efficiency of $36 \%$ from $66 \%$ in $[\mathrm{BMIM}] \mathrm{BF}_{4}$, and $31 \%$ from $63.7 \%$ in [BMIM] $\mathrm{PF}_{6}$ with mass ratios of model fuel to $\mathrm{IL}$ as $5: 1$ respectively with spent IL. Reduction of S-removal might be recognized of DBT which dissolved in IL and decreased the extraction performance of IL. These results indicated that after the IL was recycled four times, the rate of S-removal decreases slightly [29].

TABLE IV

RECYCLING OF SPENT ILS WITHOUT REGENERATION

\begin{tabular}{|c|c|c|}
\hline No. of Cycle & IL & S-removal (\%) \\
\hline 1 & \multirow{4}{*}[\mathrm{BMIM}]{$\mathrm{BF}_{4}$} & 66 \\
\hline 2 & & 55.4 \\
\hline 3 & & 48.5 \\
\hline 4 & & 36 \\
\hline 1 & \multirow{4}{*}[\mathrm{BMIM}]{$\mathrm{PF}_{6}$} & 63.7 \\
\hline 2 & & 53.4 \\
\hline 3 & & 45.2 \\
\hline 4 & & 31 \\
\hline \multicolumn{3}{|c|}{$\begin{array}{c}\text { Model fuel }=(\mathrm{n} \text {-Octane }+\mathrm{DBT}), \text { Mass ratio of model } \\
\text { fuel } / \mathrm{IL}=5: 1 \text {, Temperature }=30^{\circ} \mathrm{C} \text {, Extraction time }=30 \\
\text { min, Initial sulfur concentration }=500 \mathrm{ppmw} .\end{array}$} \\
\hline
\end{tabular}




\subsection{Desulfurization of Real Fuels using imidazolium IL}

Real fuels extraction such as diesel and gasoline is much more difficult due to its typical content of various Scompounds and other impurities. The results of extractive desulfurization of diesel and gasoline with imidazolium ILs

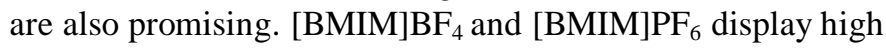
S-removal capability from diesel and gasoline in single stage extraction in $30 \mathrm{~min}$ at $30^{\circ} \mathrm{C}$ with mass ratios of 5:1 as shown in Table 5. [BMIM] $\mathrm{BF}_{4}$ and $\left[\mathrm{BMIM}^{\circ} \mathrm{PF}_{6}\right.$ exhibits the best $\mathrm{S}$ extraction ability for S-removal in diesel which was reduced from initial sulfur of $385.13 \mathrm{ppmw}$ to $210.31 \mathrm{ppmw}$ (45.4\% S-removal) and $225.19 \mathrm{ppmw}$ (41.5\% S-removal) with mass ratio of 5:1 in single stage extraction. However, in gasoline it was reduced from initial sulfur of $180.79 \mathrm{ppmw}$ to $70.2 \mathrm{ppmw}$ (61.1\% S- removal) and 90.3 ppmw (50\% S-removal) with mass ratios of 5:1 in single stage extraction. Diesel and gasoline contains more complex compounds than model fuel, such as nitrogen and sulfur containing compounds (alkylthiophene, benzothiophne) which decrease the ability of imidazolium $[\mathrm{BMIM}] \mathrm{BF}_{4}$ for S-removal. Because of steric effect of alkyl group in the aromatic rings, methyl-thiophene, methyl-benzothiophene, methyl-dibenzothiophene, etc, Scontaining compounds in diesel and gasoline are extracted less than DBT in the model fuel by ILs [30].

TABLE V

DESULFURIZATION OF DIESEL AND GASOLINE WITH [BMIM]BF ${ }_{4}$

\begin{tabular}{|c|c|c|c|c|}
\hline IL & $\begin{array}{c}\text { Diesel/IL } \\
\text { (Mass Ratio) }\end{array}$ & $\begin{array}{c}\text { S-content } \\
(\text { ppmw) }\end{array}$ & $\begin{array}{c}\text { S- } \\
\text { removal } \\
(\%)\end{array}$ & $\mathbf{K}_{\mathrm{N}}$ \\
\hline$[\mathrm{BMIM}] \mathrm{BF}_{4}$ & \multirow[t]{2}{*}{$5: 1$} & 210.31 & 45.4 & 0.83 \\
\hline$[\mathrm{BMIM}] \mathrm{BF}_{6}$ & & 225.19 & 41.5 & 0.71 \\
\hline IL & $\begin{array}{c}\text { Gasoline/IL } \\
\text { (Mass Ratio) }\end{array}$ & $\begin{array}{l}\text { S-content } \\
(\text { ppmw })\end{array}$ & $\begin{array}{c}\text { S- } \\
\text { removal } \\
(\%)\end{array}$ & $\begin{array}{r}\text { Part. } \\
\text { Coeff. } \\
\left(\mathbf{K}_{\mathrm{N}}\right)\end{array}$ \\
\hline$[\mathrm{BMIM}] \mathrm{BF}_{4}$ & $5: 1$ & 70.2 & 61.1 & 0.61 \\
\hline$[\mathrm{BMIM}] \mathrm{BF}_{6}$ & & 90.3 & 50 & 1.0 \\
\hline
\end{tabular}

\section{CONCLUSION}

Imidazolium ILs can be used for extractive desulfurization of liquid fuels, mainly with regards to those S-compounds that are very complicated to eliminate by common HDS process. $[\mathrm{BMIM}] \mathrm{BF}_{4}$ and $[\mathrm{BMIM}] \mathrm{PF}_{6}$ are the most efficient in the removal of DBT containing liquid fuels and it can reach to $66 \%$ for single stage extraction at $30^{\circ} \mathrm{C}$ in $30 \mathrm{~min}$ with mass ratio $5: 1$, which is the noteworthy progress of EDS process over HDS process. The application of very mild process conditions (low pressure and temperature) is an advantage of this new approach in comparison to HDS. The data and results of presented work might be provide significant insights of imidazolium ILs as green energy efficient solvent for extractive desulfurization of liquid fuels.

\section{ACKNOWLEDGMENT}

Authors gratefully acknowledge for the financial support by the Council of Scientific research (CSIR) grant number (22(0492)/09/EMR-II), Government of India, India (Principal Investigator: Dr. Kailas L. Wasewar).

\section{REFERENCES}

[1] Li, H. He, L. Lu, J. Zhu, W. Jiang, X. Wang, Y. and Yan, Y. (2009). Deep oxidative desulfurization of fuels catalyzed by phosphotungstic acid in ionic liquids at room temperature, Energy Fuels, 23, pp. 1354. http://dx.doi.org/10.1021/ef800797n

[2] He, L. Li, H. Zhu, W. Guo, J. Jiang, X. Lu, J. and Yan, Y. (2008). Deep oxidative desulfurization of fuels using peroxophosphomolybdate catalysts in ionic liquids, Ind. Eng. Chem. Res, 47, pp. 6890-6895. http://dx.doi.org/10.1021/ie800857a

[3] Babich, I. and Moulijin, J. (2003). Science and technology of novel process for deep desulfurization of oil refinery streams: a review, Fuel, 82, pp. 607-631.

http://dx.doi.org/10.1016/S0016-2361(02)00324-1

[4] Zhu, W. Li, H. Jiang, X. Yan, Y. Lu, J. He, L. and Xia, J. (2008). Commercially available molybdic compounds-catalyzed ultra deepdesulfurization of fuels in ionic liquids, Green Chem, 10, pp. 641-646. http://dx.doi.org/10.1039/b801185k

[5] Lo, W. Yang, H. and Wei, G. (2003). One pot desulfurization of light oils by chemical oxidation and solvent extraction with room temperature ionic liquids, Green Chem, 5, pp. 639-642. http://dx.doi.org/10.1039/b305993f

[6] Wang, R. Zhang, G. and Zhao, H. (2010) Polyoxometalate as effective catalyst for the deep desulfurization of diesel oil, Catal. Today, 149, pp.117. http://dx.doi.org/10.1016/j.cattod.2009.03.011

[7] Huang, C. Chen, B. Zhang, J. Liu, Z. and Li, Y. (2004). Desulfurization of gasoline by extraction with new ionic liquids" Energy and Fuels, 18, pp.1862-1864. http://dx.doi.org/10.1021/ef049879k

[8] Dharaskar, S. (2012). The Green solvents for petroleum and hydrocarbon industries, Res. J. of Chem. Sci. 2(8), pp. 80-85.

[9] Jiang, X. Nie, Y. Li, X. and Wang, Z. (2008). Imidazolium based alkylphosphate ionic liquids- A potential solvent for extractive desulfurization of fuel, Fuel, 87(1), pp. 79-84. http://dx.doi.org/10.1016/j.fuel.2007.03.045

[10] Dharaskar, S. Wasewar, K. Varma, M. and Shende, D. (2013). Extractive deep desulfurization of liquid fuels using Lewis based ionic liquids, Journal of Energy, pp.1-4. http://dx.doi.org/10.1155/2013/581723

[11] Bonhote, P. Dias, A. Armand, M. Papageorgiou, N. Kalyanasundaram, K. and Gratzel, M. (1996.) Hydrofobic, highly conductive ambient temperature molten salts, Inorg. Chem. 35, pp. 1168-1178. http://dx.doi.org/10.1021/ic951325x

[12] Welton, T. (1999). Room temperature ionic liquids: Solvents for synthesis and catalysis. Chem. Rev. 99, pp. 2071-2083. http://dx.doi.org/10.1021/cr980032t

[13] Song, C. Yoon, M. and Choi, D. (2005). Significant improvement of catalytic efficiencies in ionic liquids, Bull. Korean Chem. Soc. 26, pp. $1321-1330$. http://dx.doi.org/10.5012/bkcs.2005.26.9.1321

[14] Anthony, J. Brennecke, J. Holbrey, E. Maginn, R. Mantz, R. Rogers, P. Trulove, A. Visser, and T. Welton, (2003). Physiochemical properties of ionic liquids, Wiley-WCH Weinheim, pp. 41-126.

[15] Earle, M. and Seddon, K. (2000). Ionic liquids, Green solvents for the future, Pure Appl. Chem. 72, pp. 1391-1398. [16] Newington, I. PerezArlandis, J. Welton, T. (2007). Ionic liquids as designer solvents for nucleophilic aromatic substitutions. Org. Lett. 9, pp. 5247-5250.

[17] Freire, M. Carvalho, P. Fernandes, A. Marrucho, I. Queimada, A. and Coutinho, J. (2007). Surface tensions of imidazolium based ionic liquids: Anion, cation, temperature and water effect. J. Colloid Interface Sci. 314, pp. 621-630. http://dx.doi.org/10.1016/j.jcis.2007.06.003

[18] Chiappe, C. and Pieraccini, D. (2004). Kinetic study of the addition of trihalides to unsaturated compounds in ionic liquids. Evidence of a remarkable solvent effect in the reaction of $\mathrm{ICl}_{2}{ }^{-}$. J. Org. Chem. 69, pp. 6059-6064. 
http://dx.doi.org/10.1021/jo049318q

[19] Da-peng, L. Xiao-ling, H. Ya-mei, Z. Ping, G. and Jing-Yang, Y. (2010). $4^{\text {th }}$ International Conference on Bioinformatics and Biomedical Engineering (ICBBE), Study of green solvents 1-butyl-3 methyimidazoilum ionic liquids structures and properties. IEEE, pp. 1-4.

[20] Faridbod, F. Ganjali, M. Norouzi, P. Riahi, S. and Rashedi, H. (2011). Application of Room Temperature Ionic Liquids in Electrochemical Sensors and Biosensors, Ionic Liquids: Applications and Perspectives, Prof. Alexander Kokorin (Ed.), ISBN: 978-953-307-248-7, InTech.

[21] Liu, D. Gui, J. Song, L. Zhang, X. and Sun, Z. (2008). Deep desulfurization of diesel fuel by extraction with task specific ionic liquids. Petr. Sci. Technol. 26, pp. 973-982. http://dx.doi.org/10.1080/10916460600695496

[22] Sun, X. and Zhao, S. (2006). [Bmim] Cl/[FeCl3] ionic liquid as catalyst for alkylation of benzene with 1-octadecene. Chinese Journal of Chemical Engineering. 14(3), pp. 289-293. http://dx.doi.org/10.1016/S1004-9541(06)60073-6

[23] Asumana, C. Yu, G. Li, X. Zhao, J. Liu, G. and Chen, X. (2010). Extractive desulfurization of fuel Oils with low viscosity dicynamide based ionic liquids. Green Chem.12(11), pp. 2030. http://dx.doi.org/10.1039/c0gc00118j

[24] Nie, Y. Li, C. Sun, A. Meng, H. and Wang, H. (2006). Extractive desulfurization of gasoline using imidazolium based phosphoric. Energy Fuel., 20(5), pp. 2083. http://dx.doi.org/10.1021/ef060170i

[25] MuMurry, J. (1992). Organic Chemistry ( ${ }^{\text {rd }}$ edition). Brooks/Cole Publishing Company. Belmont.

[26] Chen, X. Liu, G. Yuan, S. Asumana, C. Wang, W. and Yu, G. (20120. Extractive Desulfurization of Fuel Oils with Thiazolium-Based Ionic Liquids, Sep. Sci.Techno., 47, pp. 819-826.

[27] Cun, Z. Feng, W. Xiao-yu, P. and Xiao-qin, L. (2011). Study of extractionoxidation desulfurization of model oil by acidic ionic liquid. J. Fuel. Chem. Technol. 39(9), pp. 689-693. http://dx.doi.org/10.1016/S1872-5813(11)60041-8

[28] Huang, W. Zhu, W. Li, H. Shi, H. Zhu, G. Liu, H. and Chen, G. (2010). Heteropolyanion based ionic liquid for deep desulfurization of fuels in ionic liquids. Ind. Eng. Chem. Res. 49, pp. 8998. http://dx.doi.org/10.1021/ie100234d

[29] Ge, J. Zhou, Y. Yang, Y. and Xue, M. (2011). Catalytic oxidative desulfurization of gasoline using ionic liquid emulsion system. Ind. Eng. Chem. Res. 50, pp. 13686-13692. http://dx.doi.org/10.1021/ie201325e

[30] Wang, J. Zhao, D. Zhou, E. and Dong, Z. (2007). Desulfurization of gasoline by extraction with $\mathrm{N}$-alkyl-pyridinium-based ionic liquids. J. Fuel Chem Technol, 35(3), pp. 293-296. http://dx.doi.org/10.1016/S1872-5813(07)60022-X 